\title{
Towards Addressing the Opportunities and Challenges of Web 2.0 for Health and Informatics
}

\author{
P. J. Murray, M. Cabrer, M. Hansen, C. Paton, P. L. Elkin, W. S. Erdley \\ IMIA Web 2.0 Exploratory Taskforce
}

\begin{abstract}
Summary
Objective: To provide an overview of Web 2.0 and Health 2.0, and so facilitate a widespread discussion of the nature of these concepts and their possible application within the health domain, and implications for health and biomedical informatics and for IMIA.

Methods: IMIA, the International Medical Informatics Association, has established a Web 2.0 Exploratory Taskforce to bring together interested individual s from within and outside IMIA to explore the nature and potential of Web 2.0 applications. The Taskforce aims to develop background materials and sample uses of Web 2.0 applications, so as to propose specific lines of action for the IMIA Board and General Assembly. This paper provides a brief overview of Web 2.0 and related concepts, and examples of general and healthspecific Web 2.0 applications. Some examples of the issues, challenges and opportunities are introduced, to set the scene for a wider dialogue on if, how, and how best, IMIA, and the wider health and informatics communities, should use these new applications and approaches.

Results and conclusions: This brief paper provides an introduction to, and overview of, the many issues involved in considering the application of Web 2.0 to health and informatics. All interested individuals and organisations are invited to use this as a starting point for engaging in wider discussion and contributing to the Taskforce and to IMIA's future.

\section{Keywords}

IMIA, health informatics, medical informatics, Web 2.0, Health 2.0

Geissbuhler A, KulikowskiC, editors. IMIA Yearbook of Medical Informatics 2008. Methods Inf Med 2008; 47 Supp 1 1:44-51
\end{abstract}

\section{Introduction}

The term 'Web 2.0' [1] is now widely known, although there are differing views on its precise meaning and long term implications. In this paper, members of the International Medical Informatics Association (IMIA) Web 2.0 Exploratory Taskforce [2] introduce some of the issues and challenges that Web 2.0, and its successor memes, might present for the global health and biomedical informatics communities.

The paper begins with an overview of current definitions of Web 2.0, showing how it differs from what is retrospectively termed 'Web 1.0', before providing a brief introduction to some of the main categories of Web 2.0 applications, with examples drawn from everyday use, education, and healthrelated uses. The paper introduces, as stimulus for wider discussion, some of the issues, opportunities and challenges that the global health and biomedical informatics communities, and in particular IMIA, need to address, recognising that this is not an exhaustive list. Through engaging in a widespread discussion within the community, we can determine the real implications for the future of healthcare, and the ways in which IMIA must take account of, and interact with, the phenomena. The paper introduces the aims of the IMIA Web 2.0 Exploratory Taskforce, before concluding with an brief overview of 'Health 2.0', Web 3.0, and beyond.

\section{What Is Web 2.0?}

Most current definitions of the term 'Web 2.0' refer to its being a "second generation of web-based communities and hosted services" [1], and focus on the interactive nature of Web 2.0 applications - hence, it is also referred to as the 'read-write web' [3]. It tends to be a layman's, or non-technical, term encompassing a range of technologies. Much emphasis is placed on the community-based aspects of Web 2.0 applications, wherein end-users collaborate in the generation, use and sharing of content, through applications include social-networking sites, wikis, blogs, and folksonomies.

The origin of the term 'Web 2.0', in 2003, is generally credited to Dale Dougherty, of O'Reilly Media [4], its use rapidly spreading after the first O'Reilly Media Web 2.0 conference in 2004 [5]. Some argue that Web 2.0 is not sufficiently defined, and that there is little real understanding of what it means. O'Reilly counters this, referring to Web 2.0 as not having "a hard boundary, but rather, a gravitational core" [5]. However some, including founder of the Web, Sir Tim Berners-Lee [6], suggest that, as it does not refer to any significant new or updated technical specifications, but to changes in the ways in which both enduser and developers use the World Wide Web (Web), it simply represents a progression, rather than a new paradigm. Nevertheless, we are seeing the emergence of many new applications that 
have a focus on interactivity between websites and users, with dynamic, usergenerated content, as opposed to users' simple consumption of static content. Web 2.0 is seen by many as not only a set of technologies, but a philosophy, the actor and author Stephen Fry seeing reciprocity and genuine interactivity as key; as he says, it is "all about people" [7]. A useful introduction to Web 2.0 is provided by the YouTube video, 'The machine is us/ing us' [8].

Web 2.0, compared with static 'Web 1.0' applications, allow users to read, write, view and listen online; content is added, updated, and deleted by users, facilitating social networking, collaboration, communication, education, and active participation. The value of content is also increasingly determined by users, rather than the originator; users rate (vote on), comment, annotate, and edit content, with the highest ranked items being recommended to the rest of the community. An important, but underappreciated, aspect of Web 2.0 is that minimal IT skills are needed to create a blog or a wiki, or to create a community site and develop an idea; this changes the power structure and social dynamic between service/site providers and users.

O'Reilly [5] summarises the core competencies of Web 2.0 as including trusting users as co-developers and harnessing collective intelligence (the 'wisdom of the crowd' [9]). Web 2.0 applications also imply changes in how software/services are viewed; instead of monolithic releases of new features, many applications are in 'perpetual beta', with new features being constantly released and end-users acting as real-time application testers. In philosophical terms, this can be seen as a change from a modernist perspective (grand monoliths, everything has to be finished before release) to a more post-modernist attitude (fluidity, flexibility, change).
Web 2.0 is therefore latterly being defined with more focus on social interactions and architectural implementation, as "a knowledge-oriented environment where human interactions generate content that is published, managed and used through network applications in a service-oriented architecture" [10]; what Decrem terms the "participatory web" [11].

\section{Some Common Web 2.0 Tools}

Blogs, podcasts, and wikis [12] are among common Web 2.0 tools that are being actively explored for their use in healthcare and health/biomedical informatics contexts, in particular in digital learning environments to enhance learning experiences through engagement and collaboration $[13,14]$. Other applications offer the development of online social networks that may overlap with existing face-to-face networks, or allow the creation of new networks among people separated by space and time zone.

Web 2.0 applications make use of a range of technologies [1], through combinations of:

- AJAX (Asynchronous JavaScript and XML) programming (the site's interactivity, speed, and functionality are increased, as only small amounts of data are exchanged with the server);

- Cascading Style Sheets (CSS) (to aid in the separation of presentation and content);

- microformats (web-based data formatting that re-uses existing content as metadata);

- folksonomies (collaborative creation and management of tagging, classification and indexing to annotate and categorize content; in contrast to traditional subject indexing, metadata is generated by creators and consumers of the content, not just by experts);
- syndication, aggregation and notification of frequently updated content, such as blog entries, news headlines or podcasts, though RSS (RDF Site Summary, or "Really Simple Syndication") or other feeds;

- user-generated content provided through blog-publishing, wiki or forum software;

- mashups (web applications that merge content from different sources into a single integrated tool).

Blogs facilitate the dissemination of information and create an arena for social networking through "a hierarchy of text, images, media objects and data, arranged chronologically, that can be viewed in an HTML browser" [15]. Blogs are usually edited and published using a Content Management System (CMS), many of which are built with Linux/Apache/MySQL/PHP (LAMP) open source architecture [16]. An increasing number of applications also link or aggregate posts from different blogs having similar subjects, using either permalinks or tags.

Information delivery and personal expression is not limited to written text, but increasingly via personal audio broadcasting in forms such as podcasting, a portmanteau of 'broadcasting' and 'iPod' (Apple Computer's MP3 player). Podcasts can be distributed via RSS feed and listened to on almost any device, providing creative opportunities for truly 'any time, any place' distance education. Enhanced podcasting, a relatively new addition to personal broadcasting, includes text, images and video $[12,17]$.

Wikis are dynamic, group-developed web pages with content that may be updated or changed by anyone visiting the website. They allow for asynchronous group socialisation, communication and collaboration, and are a tool for archiving documents, brainstorming, and collaborative writing. The most well-known is Wikipedia (www. 
wikipedia.org), the online editable encyclopaedia.

Education is the domain that has witnessed most exploration of the potential of Web 2.0 tools, where social applications that facilitate student-centred collaborative learning are increasingly challenging teacher-centred pedagogies [18]. Podcasting can be used for archiving and distributing lectures in video or audio format, while video and slide sharing websites (e.g. Slideshare - www.slideshare.net) can be used to publish lectures and conference presentations more widely. Teachers and learners are also turning to video-sharing sites such as YouTube (www.youtube.com) to find and distribute educational materials [19]. At the University of Otago, one of the authors (CP) uses Skype, the peer-to-peer Voice-over-IP (VoIP) tool that allows video-conferencing, audio-conferencing and live chat with groups of students, for conducting online meetings with distance students on the health informatics course.

Tools such as blogs, wikis and online discussion forums have risen to prominence because they allow large numbers of users to interact on open access websites. Their use on closed intranets may limit their usefulness. Web 2.0 tools are useful for individuals who access computers from different locations; social bookmarking services such as Del.icio.us - .http://del.icio.us) facilitate 'update once, access from anywhere' saving and sharing of hyperlinks, while mobile professionals can use collaborative document sharing, authoring, and editing (e.g. Google Docs - http:// docs.google.com), interact with online communities (e.g. social networking sites such as MySpace - http:// myspace.com), or access resources (e.g., podcasts, YouTube videos, photographs, and other online resources, e.g., http://flickr.com/services) ([20].
However, we must also recognise that, while many end-users access content, it is created by relatively few. Despite the ease with which almost anyone now can create content, the $1 \%$ rule is an emerging rule of thumb which suggests that, for each 100 people online, one will create content, 10 will "interact" with it (comment or offer improvements), and the other 89 will just view it [21].

\section{Some Emerging Web 2.0 Applications in Health}

Web 2.0 applications offer opportunities for health professionals and patients to have open access to information and share ideas, questions, and opinions. The increasing use of the Internet by patients to access health information has been widely discussed (e.g., [22, 23, $24]$ ), as has the quality and reliability of information $[25,26]$ and the impact on the relationship between the patient and the health professional [27]. As health information websites become increasingly interactive, offering more opportunities for building communities around specific health and disease issues, new challenges will emerge.

Several Web 2.0 applications have been developed within the health domain, although most are targeted at specific audiences, i.e., either patients and family carers, or health professionals, with few appealing to, or targeting, both. This in itself raises issues for the future evolution of Web 2.0 health sites. Many blogs are dedicated to health issues, some provided by patients sharing their own health and disease experiences (e.g., "my Breast Cancer blog" - cancerspot.org; Diabetes mine -www.diabetesmine.com), while others are provided by and for health professionals (e.g., Clinical Cases and
Images - casesblog.blogspot.com; All scrubbed up - allscrubbedup. blogspot.com). "Running a hospital" (/runningahospital.blogspot.com) is a blog started by the CEO of a large hospital to share thoughts about hospitals, medicine, and health care issues. Health 2.info (http://health2.info) is a health news platform, where users can post news and vote for the most interesting or popular items; the content is not managed by an individual or small group, but the site forms a social bookmarking space for any interested audience. Others blogs are devoted specifically to health informatics, e.g. Informaticopia (www.rodspace.co.uk/ blog/blogger.html) and Health Informatics Blog (healthinformaticsblog. com). HITSphere (www.hitsphere. com) provides a good aggregation of leading health and medical informatics blogs, while some Taskforce members (PM, MH, WE) have explored using blogs for conference reports and informal professional development (www.hiblogs.info).

However, blogs are not the only Web 2.0 application with utility in health. Yensen has explored using RSS feeds for providing current awareness tools on health issues [28], Perry has used free personalized home pages (e.g., iGoogle - www.google.com/ig; Pageflakes - www.pageflakes.com) for aggregating content and making it available in nurse education contexts [29]. There are growing numbers of health and informatics communities developing within large social networking sites (e.g., Facebook), or being developed by end-users through tools such as Ning (www.ning.com), which allows creation of social network sites.

Several web 2.0 sites have been developed for physicians. Sermo (www.sermo.com) is an online community exclusively for physicians to share content and discuss issues, while 
PeerClip (www.peerclip.com) provides for health literature review and interaction with peers for health professionals. MDPIXX (mdpixx.com) is a Web 2.0 site for physicians from around the world, facilitating interchange of medical images and videos which can be evaluated by the medical community, and for creating, discussing and evaluating clinical cases. MDPIXX can also be used for research purposes and telemedicine services. All information is arranged using a comprehensive clinical terminology (SNOMED) that provides clinical content and multilingual support. Several of these sites are developed by and as end-user communities, although large commercial organisations, including publishers, are now beginning to explore the potential, as evidenced by Elsevier's launch of Wiserwiki (www.wiserwiki.com), designed to allow physicians to collaborate on developing medical information online that can be viewable by anyone.

Mashups (hybrid web applications that combine data from several sources into a single integrated tool) are increasingly popular Web 2.0 applications; many are based on the use of Google Maps (maps.google.com) for data presentation. There are currently few health-related mashups, although HEALTHmap (healthmap.org) exemplifies what can be done. It is a global disease alert map, developed by infectious disease researchers, that shows where more than 50 diseases have been reported around the world, and how "hot" an outbreak is, based on the number of reports.

\section{What Is Health 2.0, etc?}

As the Web 2.0 meme has spread, people have added the '2.0' label to many existing terms; the emergence of "Health 2.0" was inevitable. As with Web 2.0, the definition of Health 2.0 is still under discussion. While some have quickly, and perhaps too simplistically, described it as application of the Web 2.0 phenomenon to healthcare, others believe it to be much more, and to have potentially profound implications for the whole nature of the healthcare industry in all countries, and the ways in which patients and health professionals interact. Health 2.0 may go far beyond just the pervasive social networking technology of Web 2.0 to support a complete reinvention in the way that healthcare is delivered. A current working definition is that Health 2.0 is a "new concept of healthcare wherein all the constituents (patients, physicians, providers, and payers) focus on healthcare value (outcomes/ price) and use competition at the medical condition level over the full cycle of care as the catalyst for improving the safety, efficiency, and quality of health care" [30].

Shreeve suggests that Health 2.0 is "all about Patient Empowered (not the misnomer "Consumer Directed") Healthcare whereby patients have the information they need to be able to make rational healthcare decisions" [31], and that interoperability of health information will be a crucial determinant of success or failure of the movement. O'Grady believes that the most important aspect of using Web 2.0 in health care is the use of social software, which will promote collaboration between patients, their caregivers, and health professionals [32]. The development of Personal Health Record (PHR) systems (such as Microsoft ${ }^{\circledR}$ HealthVaultTM, Google Health and myPHR - http:// www.myphr.com) will raise many issues for the future nature of healthcare. Health 2.0 is a new concept; how it will evolve remains to be seen, and espe- cially whether it will provide a revolution in healthcare, but health informaticians need to be involved in the discussions and processes.

\section{Challenges, Opportunities and Implications of Web 2.0 for Health and Informatics}

If the hyperbole around Web 2.0, Health 2.0, etc. translate to real changes in the ways in which health is maintained, care delivered, and patients, family and health professionals (including health informaticians) interact, then all involved will face many challenges to the ways in which they currently work. However, Web 2.0 will bring many other challenges and opportunities to the health domain, to health informatics, and to organisations such as IMIA. We cannot, especially in this short introductory paper, predict them all, and new ones will emerge as generic Web 2.0 applications are increasingly used within health, adapted for use by patients and health professionals, as well as healthcare provider organisations, and as Health 2.0 applications become widespread. The key elements of Web 2.0 are community and interaction; it is in these areas that the greatest opportunities arise for change, but also the greatest challenges exist to current practice.

As health and medical informatics strive to have positive impacts on healthcare, we will need to increasingly look to new models of collaboration and group practice in medicine, nursing, and other health professions. As communication is key to good clinical practice in all health professions - clinicians communicating with patients, and with other clinicians and healthcare personnel Web 2.0 applications can be explored to provide increasingly collaborative 
care as the basis for 21st Century healthcare. We can already see some examples emerging, as discussed above, but together with new forms of collaboration will come opportunities to imagine new workflows and work patterns. New types of collaborative workflow will be based in greater access to more information, much of which is user-generated and context-specific to the health needs of individuals. It will also present challenges in the management of that information. Such new patterns might help to break down some of the artificial barriers that lead to medical errors, and might encourage cross-disciplinary improvements to patient care, medical education and research. Such new interactions, and emerging new workflows, pose challenges, however, to people wedded to current patterns of power relationships within the interaction between patients and health professionals, and among health professionals. New attitudes and mindsets, that see these new forms of interaction as liberating, rather than threatening, will not be easily adopted by all.

Health and medical informatics, and the professionals who work in the domains, are uniquely suited to provide the data, guidance and leadership for how Health 2.0 should be developed out of the current Web 2.0 models. Working together with those in primary healthcare disciplines (as in many countries, moves are under way to make healthcare more based in primary care, health maintenance and disease prevention), we can potentially change the way we practice medicine and healthcare, creating a safer and more effective, and lower cost, healthcare system.

However, this is premised in health and medical informatics professionals being aware of, and having the skills in, developing and using Web 2.0 technologies. There are two seemingly contra- dictory, but interlocking, factors that raise the possibility of health informatics being bypassed, even made redundant, by the emergence of Health 2.0. On the one hand, Web 2.0 applications are increasingly designed so that the end-user requires only basic computing skills to undertake what, previously, would have needed sophisticated levels of knowledge and skill. Today, almost anyone can set up a blog, or a wiki, or input content to many types of Web 2.0 application, due to the ready availability of suites of online tools. Some of these skills would very recently have been seen, and perhaps still are seen, as the skills of health informatics and computing professionals. Even the health informatics specialisms focused around classification of data and terminologies are being potentially bypassed by the emergence of folksonomies, user generated tagging systems. On the other hand, we see little evidence of health informatics professionals and organisations making use of Web 2.0 applications. While there have always been and continue to be individual pioneers exploring new and emerging technologies (including, now, Web 2.0), few health and medical informatics organisations have used Web 2.0 applications to engage with their members, deliver services, or explore the development of health-specific applications. Unless these issues are addressed, we run the risk of health informatics being bypassed as a profession, and its relevance increasingly questioned. Why, people will ask, do we need health informaticians when we can do all these things ourselves?

Many other challenges and opportunities undoubtedly exist and will arise, over and above the simpler technical issues around authorship and site vandalism [13]. The success of Wikipedia demonstrates that problems of authorship and vandalism can be overcome with vigilance and community goodwill. Health professionals will need to be able to put their case for the best evidence and argue convincingly for the online community to accept their opinions. Institutional authority and qualifications will count for less in the online world, but persuasive argument and verifiable facts will probably count for more. The privacy implications of widespread consensual data sharing, identity management, whether some sections of the population may be disenfranchised by the creation of further 'digital divides', and which tools might best support which types of online communities or activities are only a few areas to explore.

We raise one further point for consideration. The evolution of Web 2.0 applications, and the move towards Web 3.0, are happening very rapidly. As such, we are unlikely to be able to afford, in any sense of the word, to wait for the outcomes of formal, long-term experimental studies, but will need to rely on rapid pilot-testing and action research to give indications of the best routes and solutions.

\section{What IMIA Is Doing - the Web 2.0 Taskforce}

The first step for any organisation in making appropriate use of new and emerging technologies is to develop a knowledge of them and awareness of their possibilities. In exploring the potential of Web 2.0 applications and approaches, both within its own organisational structure and activities, and their wider application within health and biomedical informatics, IMIA has established a Web 2.0 Exploratory Taskforce [2]. This Taskforce will contribute to the IMIA Strategic Plan (Towards IMIA2015) which en- 
visions IMIA as being "recognized as an inclusive global association that connects groups and individuals at the leading edge of the state of the art of the field of health and biomedical informatics, within and without the IMIA community, in order to advance, develop and disseminate the (art and) science of informatics in support of health" [33]. The Strategic Plan makes specific reference, inter alia, to IMIA providing for:

- outstanding communications (in all senses), e.g. web services/collaborative tools, newsletters, conferences, etc.;

- the e-Agora for academic exchanges;

- the exploration and integration of appropriate technologies.

The Taskforce is developing background and discussion papers (including this paper) to facilitate informed discussion among IMIA's members and decision making by IMIA's governing bodies. It brings together interested individuals from within IMIA, as well as seeking to draw on outside expertise, to explore the nature and potential of Web 2.0 applications, including the implications of emerging Health 2.0 applications based around personal health records such as the recent developments exemplified by Microsoft's Health Vault and Google Health. In addition, the Taskforce is piloting the use of Web 2.0 tools, to assess their potential and provide evidence for recommendations for their wider adoption in future provision of IMIA's services. For example, a portal for co-ordinating and disseminating the Taskforce's activities has been built, using the Drupal open source CMS (www.differanceengine.net/imia20) and incorporating a range of Web 2.0 applications, including RSS feeds, wiki-like resource development, social bookmarking and blogs. A pilot social networking site has been built, using the Ning free online tool (http://imia20.ning.com) to allow Taskforce members and others interested in these activities to explore the potential of such sites for IMIA's services and interactions with members. In addition, unofficial IMIA groups have been established by IMIA members on two popular social and professional networking sites, i.e. Facebook ( www. facebook.com/g rou p. php?gid=5675909898) and LinkedIn (www.linkedin.com) to explore the potential of social networking for health informatics organisations. Reports and recommendations arising from the work of the Taskforce will inform the future direction and development of IMIA.

\section{Beyond Web 2.0 - Web 3.0 and Web3D}

With the emergence of Web 2.0, it was inevitable that people would discuss what followed - Web 3.0, and beyond. While some suggestions may have been frivolous, there is emerging serious discussion of Web 2.0 being a staging post on the path to the convergence of several technologies. The term "Web 3.0" began to have serious use in 2006. While it has been used to describe several possible scenarios of evolution of Web usage and interaction along different paths, one widely cited description sees it as being more connected, open, and intelligent, using semantic Web technologies, distributed databases, natural language processing, machine learning, and autonomous agents, so moving away from separately silo applications and content repositories [34]. Others also see the integration of the Geospatial Web (the merging of location-based information with the abstract information that currently domi- nates the Internet), which would create an environment where one could search for things based on location instead of by keyword [35] or the 3D Web [36], of virtual environments and avatars.

Spivack sees Web 3.0 as being dependent on, or facilitating, the convergence of several major technology trends that are likely to reach maturity within the next 5 years, and will mutually reinforce, and collectively drive, the thirdgeneration Web. The convergent trends include ubiquitous connectivity (through widespread broadband Internet access and mobile devices), network and distributed computing (P2P, grid computing, hosted "cloud computing" server farms such as Amazon S3), open technologies (open APIs, open source software platforms and open data, such as Creative Commons and Open Data License), and open identity (applications such as OpenID, open reputation and portable identity and personal data). All of these developments are seen as creating an "Intelligent Web", based in Semantic Web technologies, distributed databases and intelligent applications [34].

Other parallel technological developments, while perhaps not being central to the nature of Web 2.0 and beyond, are likely to interact with, and have impact on, the development of Web 3.0 applications. We are likely to see increased miniaturization of hardware which would influence the kinds of increasingly mobile devices available, proliferation of computational devices in everyday life (technology becoming 'transparent', wearable computing devices becoming mainstream (including health monitoring devices), 24/7 monitoring of device output (with implications, for example, for health monitoring), changes to health care models at local and global levels, and real-time large dataset analysis (e.g. of genomic data) [37]. 
Three-dimensional (3D) virtual worlds such as the popular Second Life (http:/ /secondlife.com) and Second Health (http://secondhealth.wordpress.com) platforms are being explored as places to meet others online. The pedagogical potential associated with these $3 \mathrm{D}$ social networks is being actively explored for medical and health education [38]. The Idaho Bioterrorism Awareness and Preparedness Program (http:// www.ibapp.org) is responsible for the creation of 'Play2Train,' an immersive 3D hospital and town built on the Second Life platform that enables individuals to practice medical skills in a simulated environment [39]. A wide variety of scenarios and virtual infrastructures simulate fires, explosions and different weather conditions; such 3D multiuser environments for health care training are becoming popular because they do not take up physical space, practice in multiple scenarios without set-up costs, and the program may be accessed anywhere at any time. Another 3D virtual simulation example is the Web3D Exchange (http://web3dexchange.org/ joomla), part of the ALIVE project, whose aim is to enhance teaching and learning experiences by combining Web3D technologies with e-learning strategies for unique educational experiences.

\section{Conclusion}

This paper has provided a brief overview of Web 2.0, related memes such as Health 2.0, and some possible future directions in the emergence of Web 3.0 and beyond. These have been presented to illustrate emerging new technologies and applications, some of which are being rapidly adopted by millions of everyday users, that may have utility for healthcare and for health informatics, and that the international health and biomedical informatics communities therefore need to explore. We are not proposing the uncritical adoption of any of these technologies, and the paper poses questions that the community and the IMIA Taskforce need to explore. Responsible organisations such as IMIA need to take a leading role, within their mission, in critically examining these new developments and determine if, how, and how best they can be used to support the ultimate goal of improving the health of the global population. The IMIA Web 2.0 Exploratory Taskforce welcomes the involvement in our discussions of anyone interested in these new and exciting developments.

\section{References}

1. Wikipedia [homepage on the Internet]. Web 2.0; [updated 2008 Jan 15; cited 2008 Jan 15]. Available from: http://en.wikipedia.org/wiki/Web_2.

2. Murray PJ, Moura Jr LA. IMIA Web 2.0 Taskforce website - Taskforce scope [homepage on the Internet]; [updated $2007 \mathrm{Dec} 10$; cited 2008 Jan 15]. Available from: http://www.differanceengine.net $/$ imia20/node/3

3. Gillmor, D. The Read-Write Web. In: Gillmor, D. We the Media - Grassroots Journalism by the People, for the People. Sebastopol, CA: O'Reilly Media Inc; 2004. Available from: http://www.oreilly.com/ catalog/wemedia/book/ch02.pdf

4. Wikipedia [homepage on the Internet]. O'Reilly Media; [updated 2008 Jan 09; cited 2008 Jan 15]. Available from: http://en.wikipedia.org/wiki/ O\%27Reilly_Media

5. O'Reilly, T. What Is Web 2.0 - Design Patterns and Business Models for the Next Generation of Software.[monograph on the Internet]; 2005 Sep 30. [cited 2008 Jan 15]. Available from: http:// www.oreillynet.com/pub/a/oreilly/tim/news/2005/ 09/30/what-is-web-20.html

6. Anderson, N. Tim Berners-Lee on Web 2.0:"nobody even knows what it means". ars technica [serial on the Internet]; 2006 Sep 01. [cited 2008 Jan 15]. Available from: http://arstechnica.com/news.ars/ post/20060901-7650.html.

7. Zambonini D. Is Web 2.0 killing the semantic web? [monograph on the Internet]; 2005 [cited 2008 Jan 15]. Available from: http://www.oreillynet.com/pub/ wlg/8013.

8. Wesch M. YouTube video, The machine is us/ing us (final version). [video on the Internet]; 2007 [cited 2008 Jan 15]. Available from: http://
uk.youtube.com/watch?v=NLlGopyXT_g

9. Surowiecki JM. The Wisdom of Crowds: Why the Many Are Smarter Than the Few and How Collective Wisdom Shapes Business, Economies, Societies and Nations. Little, Brown; 2004.

10. de Judicibus D. World 2.0. L'Independente [serial on the Internet]; 2008 Jan 02 [cited 2008 Jan 15]. Available from: http://indipendente.splinder.com/ post $/ 15354690 /$ World +2.0

11. Decrem B. Introducing Flock Beta 1. Flock official blog. [weblog on the Internet]; 2006 Jun 13 [cited 2008 Jan 15]. Available from: http:// www.flock.com/node/4500

12. Murray PJ, Maag M. Towards Health Informatics 2.0: Blogs, Podcasts and Web 2.0 Applications in Nursing and Health Informatics Education and Professional Collaboration. [monograph on the Internet]; 2006. [cited 2008 Jan 15] Available from: http://www.differance-engine.net/hiblogs/media/ publications/murraymaaghi20\%20july06.rtf

13. Boulos MNK, Maramba I, Wheeler S. Wikis, blogs and podcasts: a new generation of Web-based tools for virtual collaborative clinical practice and education. BMC Medical Education [serial on the Internet];2006; 6:41. Unique ID:10.1186/14726920-6-41. [cited 2008 Feb 25]. Available from: $\mathrm{http}: / /$ www.biomedcentral.com/1472-6920/6/41

14. Boulos MNK, Wheeler S. The emerging Web 2.0 social software: an enabling suite of sociable technologies in health and health care education. Health Info Libr J 2007 Mar;24(1):2-23.

15. Winer D. What makes a weblog a weblog? Weblogs at Harvard Law. [monograph on the Internet]; 2003. [cited 2008 Jan 15]. Available from: http:// www.scripting.com/davenet/2003/06/18/ whatMakesAWeblogAWeblog.html

16. Murray P, Øyri K. Developing online communities with LAMP (Linux, Apache, MySQL, PHP) - the IMIA OSNI and CHIRAD experiences. In: Engelbrecht R, Geissbuhler A, Lovis C, Mihalas $\mathrm{G}$, editors. Connecting medical informatics and bio-informatics: Proceedings of MIE2005; 2005 August 28-31; Geneva Switzerland. Amsterdam: IOS Press; 2005. p. 361-6.

17. Maag M. Podcasting and MP3 players: emerging education technologies. CIN: Computers, informatics, nursing. 2006; 24(1):9-13.

18. Barnes C, Tynan B. The adventures of Miranda in the brave new world: learning in a Web 2.0 millennium. ALT-J, Research in Learning Technology. 2007;15(3):189-200.

19. Skiba DJ. Nursing Education 2.0: YouTube. Nursing Education Perspectives. 2007;28(2):100-102.

20. Boulos MNK. e-Health and Web 2.0: Looking to the future with sociable technologies and social software. [monograph on the Internet]; 2007 [cited 2008 Jan 15]. Available from: http:// healthcybermap.org/sl.htm

21. Arthur C. What is the $1 \%$ rule? The Guardian. [serial on the Internet]; $2006 \mathrm{Jul} 20$ [cited $2008 \mathrm{Jan}$ 15]. Available from: http://www.guardian.co.uk/ $\mathrm{technolog} \mathrm{y/2006/ju} 1 / 20 /$ guardianweeklytechnologysection2

22. Ayantunde AA, Welch NT, Parsons SL. A survey of patient satisfaction and use of the internet for health information. Int J Clin Prac 2007;61(3):458-62.

23. Diaz JA, Griffith RA, Ng JJ, Reinert SE, Friedmann PD, Moulton AW. Patients' Use of the Internet for 
Medical Information. J Gen Intern Med. 2002;17(3):180-185.

24. LaCoursiere SP, Knobf MT, McCorkle R. Cancer Patients' Self-Reported Attitudes About the Internet. $\mathrm{J}$ Med Internet Res [serial on the Internet]; 2005;7(3):e22. [cited 2008 Jan 15]. Available from: http://www.jmir.org/2005/3/e22/

25. Seidman JJ, Steinwachs D, Rubin HR. Design and Testing of a Tool for Evaluating the Quality of Diabetes Consumer-Information Web Sites. J Med Internet Res [serial on the Internet]; 2003;5(4):e30. [cited 2008 Jan 15]. Available from: http:// www.jmir.org/2003/4/e30/

26. Bates B, Romina S, Ahmed R, Hopson D. The effect of source credibility on consumers' perceptions of the quality of health information on the Internet. Med Inf and Internet Med 2006;31(1):45-52.

27. Stevenson F, Kerr C, Murray E, Nazareth I. Information from the Internet and the doctor-patient relationship: the patient perspective - a qualitative study. BMC Fam Pract 2007; 8:47. Unique ID: 10.1186/1471-2296-8-47. Available from: http:// www.biomedcentral.com/bmcfampract/

28. Yensen JAP. Leveraging RSS Feeds to Support Current Awareness. CIN Plus. CIN:Computers, Informatics, Nursing 2005; 23(3):164-7.

29. Perry W. Notes from the Net Nomad. CIN Plus.
CIN:Computers, Informatics, Nursing 2006; 24(6); 305-6.

30. Health 2.0. [homepage on the Internet]. [updated 2007 Dec 2; cited 2008 Jan 15]. Available from: http://http://health20.org/wiki/Main_Page

31. Shreeve S. What is Health 2.0:The Enabling Technologies and Reform Initiatives for Next Generation Health Care. [monograph on the Internet]; 2007 Oct 14 [cited 2008 Jan 15]. Available from: h t t p : / / h e a $1 \mathrm{th} 20$. org / w i k i / Shreeve_Health_2.0_Whitepaper

32. O' Grady L. Health 2.0 definition: what about eHealth 2.0? [homepage on the Internet] $2007 \mathrm{Oct}$ 13 [cited 2008 Jan 15]. Available from: http:// health20.org/wiki/Health_2.0_Definition

33. Lorenzi N. Towards IMIA 2015 - the IMIA Strategic Plan. In: IMIA Yearbook of Medical Informatics 2007. Methods Inf Med 2007;46 Suppl 1:1-5.

34. Spivack N. The Third-Generation Web is Coming [monograph on the Internet]; 2006 Dec 17 [cited 2008 Jan 15]. Available from: http:// www.kurzweilai.net/meme/frame.html?main=/articles/art0689.html

35. Scharl A, Tochtermann K. (Eds.) The Geospatial Web. How Geobrowsers, Social Software and the Web 2.0 are Shaping the Network Society. London: Springer; 2007
36. Wikipedia [homepage on the Internet]. 3D_web; [updated 2008 Jan 13; cited 2008 Jan 15]. Available from: http://en.wikipedia.org/wiki/3D_web

37. Murray PJ, Park H-A, Erdley WS, Kim J, editors. Nursing Informatics 2020: Towards Defining our own Future. Proceedings of NI2006 Post Congress Conference. Amsterdam: IOS Press; 2007.

38. Boulos MNK, Hetherington L, Wheeler S. Second Life: an overview of the potential of 3-D virtual worlds in medical and health education. Health Information Libraries Journal 2007, 24(4):233-45.

39. Play2train. [homepage on the Internet]; 2007 [cited 2008 Jan 15]. Available from: http:// irhbt.typepad.com/play2train/

\section{Correspondence to:}

Dr. Peter J. Murray

IMIA Interim Vice President for Strategic Planning Implementation Coachman's Cottage

Nocton Hall, Nocton

Lincoln

United Kingdom

E-mail: peterimurray@gmail.com

www.imia.org 